\title{
Polypoidal Choroidal Vasculopathy: Clinical Features and Genetic Predisposition
}

\author{
Shigeru Honda Wataru Matsumiya Akira Negi \\ Division of Ophthalmology, Department of Surgery, Kobe University Graduate School of Medicine, Kobe, Japan
}

\author{
Key Words \\ Polypoidal choroidal vasculopathy · Choroidal \\ neovascularization · Clinical features · Genetic \\ predisposition
}

\begin{abstract}
Polypoidal choroidal vasculopathy (PCV) is currently recognized as a phenotype of age-related macular degeneration (AMD). PCV is believed to be a type of choroidal neovascularization, although some cases of PCV show a distinct vascular abnormality of the choroidal vessels. PCV often shows several unique clinical manifestations which are apparently different from typical neovascular AMD (tAMD). In addition, the natural course and response to treatment are often different between TAMD and PCV. Moreover, recent genetic studies suggested a possible difference in the genetic susceptibility to disease between $\mathrm{AMD}$ and PCV, as well as the existence of heterogeneity among PCV cases. In viewing the accumulation of knowledge about PCV, we have summarized the recent literature regarding PCV in this review article to improve the understanding of this clinical entity including possible susceptibility genes. We will also discuss the optimal treatment strategies for PCV in accordance with the results of recent clinical and genetic studies.
\end{abstract}

(c) 2013 S. Karger AG, Basel

\section{KARGER}

E-Mail karger@karger.com

www.karger.com/oph

\section{Introduction}

Polypoidal choroidal vasculopathy (PCV) was first described in the early 1980s and was originally thought to be a distinct abnormality of the choroidal vasculature found in the peripapillary area [1-3]. However, subsequent reports showed a broad clinical spectrum of $\mathrm{PCV}$, and some authors suggested that PCV is a type of choroidal neovascularization (CNV) [4-6]. Hence, PCV is currently categorized as a phenotype of age-related macular degeneration (AMD), and most ophthalmologists believe that PCV is a type of CNV caused by AMD, although some reports suggested that some cases of PCV are indeed a distinct vascular abnormality of the choroidal vessels. PCV often shows several unique clinical manifestations which are apparently different from typical neovascular AMD (tAMD). For example, distinct polypoidal lesions are the most characteristic feature of PCV (fig. 1). PCV is often found in the extramacular area, whereas tAMD always exists within the macular area $[7,8]$. In addition, the natural course and response to treatment are often different between tAMD and PCV [9-17]. Moreover, recent genetic studies suggested a possible difference in the genetic background between tAMD and PCV [18-25], as well as the existence of heterogeneity among PCV cases [26, 27]. Considering the accumulated knowledge about PCV, we now have to reconsider the rationale for understanding and treating this clinical entity. In this

Shigeru Honda, MD, PhD

Division of Ophthalmology, Department of Surgery

Kobe University Graduate School of Medicine

7-5-2 Kusunoki-cho, Chuo-ku, Kobe 650-0017 (Japan)

E-Mail sighonda@med.kobe-u.ac.jp 

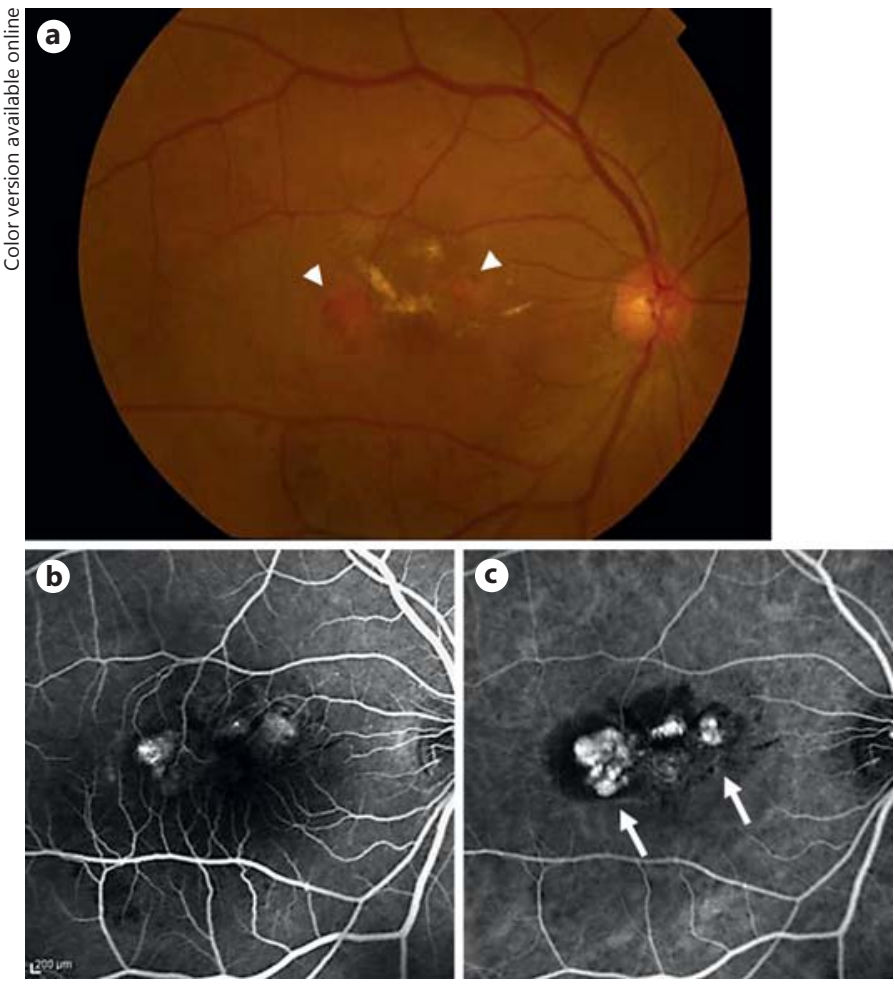

Fig. 1. Fundus photography, fluorescein angiography and indocyanine green angiography images of PCV. a Orange-red lesions (arrowheads) are found at the posterior pole of the retina. b Dye leakage occurred from the lesions in fluorescein angiography. c Distinct polypoidal lesions (arrows) are found in indocyanine green angiography.

review article, the recent literature regarding PCV is first summarized to understand the clinical presentation of PCV, which can be divided into: (1) the common features between PCV and tAMD, and (2) some unique characteristics that are considered specific for PCV. Second, the possible genetic factors responsible for the phenotypes of PCV are introduced. Third, the optimal treatment strategies for PCV are discussed.

\section{Epidemiology}

The age range of the patients in previous reports [13, $28,29]$ was $21-93$ years, and the mean was 68.4 years. $\mathrm{PCV}$ is more prevalent in Asian and African-American populations than Caucasians, which may cause the heterogeneity in the clinical features of AMD among the races. Previous studies reported that PCV accounts for 23.0 $54.7 \%$ of patients with neovascular AMD in the Japanese
$[11,20,30], 49 \%$ in the Taiwanese [31], 22.3-24.5\% in the Chinese [32,33] and $22.2-24.6 \%$ in the Korean populations $[34,35]$, but in only about $8-13 \%$ of Caucasians [36]. African-Americans are also known to be susceptible to PCV, although no epidemiological study for black people has been reported to date. PCV is more prevalent in men than women in Asian populations (22-37\% female), but the opposite is observed in Caucasians (52-65\% female) [28]. It is also reported that PCV often affects African-American women. Bilateral cases were reported in 9-18\% of Asians (Japanese) and $21-55 \%$ of Caucasians. The majority of PCVs (62-94\%) are located in the macular area in Asian cohorts, but peripapillary PCV (fig. 2) was frequently observed (18-75\%) in American and European cohorts [28]. Moreover, PCV can be located outside the posterior vascular arcade, which may cause peripheral exudative hemorrhagic chorioretinopathy $[7,8]$. In some PCV cases, a lesion beneath the macula and remote lesions are found simultaneously [37]. It is unknown why such ethnic variation exists in the epidemiology of PCV. Recent genetic studies suggested that some genetic factors may be associated with the clinical feature of PCV, which could be the reason for such ethnic variations in PCV.Several studies have determined the systemic and ocular risk factors of PCV. They reported that 41$45 \%$ of PCV patients had systemic hypertension [38-40]. Another report demonstrated that C-reactive protein levels were increased in patients with PCV [41]. Cigarette smoking is a potent risk factor for PCV [42], and a history of central serous chorioretinopathy was a significant risk factor for PCV [38].

\section{Clinical Manifestation}

In accordance with the literature, $\mathrm{PCV}$ is characterized by: (1) orange-red colored protrusions at the posterior pole of the retina (or sometimes at the peripheral retina), and/or (2) polypoidal lesions found by indocyanine green angiography (ICGA; fig. 1). However, polypoidal lesions may not be found due to hemorrhage blockage or insufficient image quality in some cases, which makes the diagnosis of PCV difficult. Such cases may be classified as 'suspected of PCV' [43], but it is often very difficult to distinguish those cases from tAMD.

The PCV lesions usually appear as reddish or nonreddish pigment epithelial detachments (PEDs) and are occasionally accompanied by serous retinal detachment (SRD), subretinal hemorrhage, subretinal fibrinous material, hard exudates and drusens. The funduscopic find-
60

Ophthalmologica 2014;231:59-74 DOI: $10.1159 / 000355488$
Honda/Matsumiya/Negi 

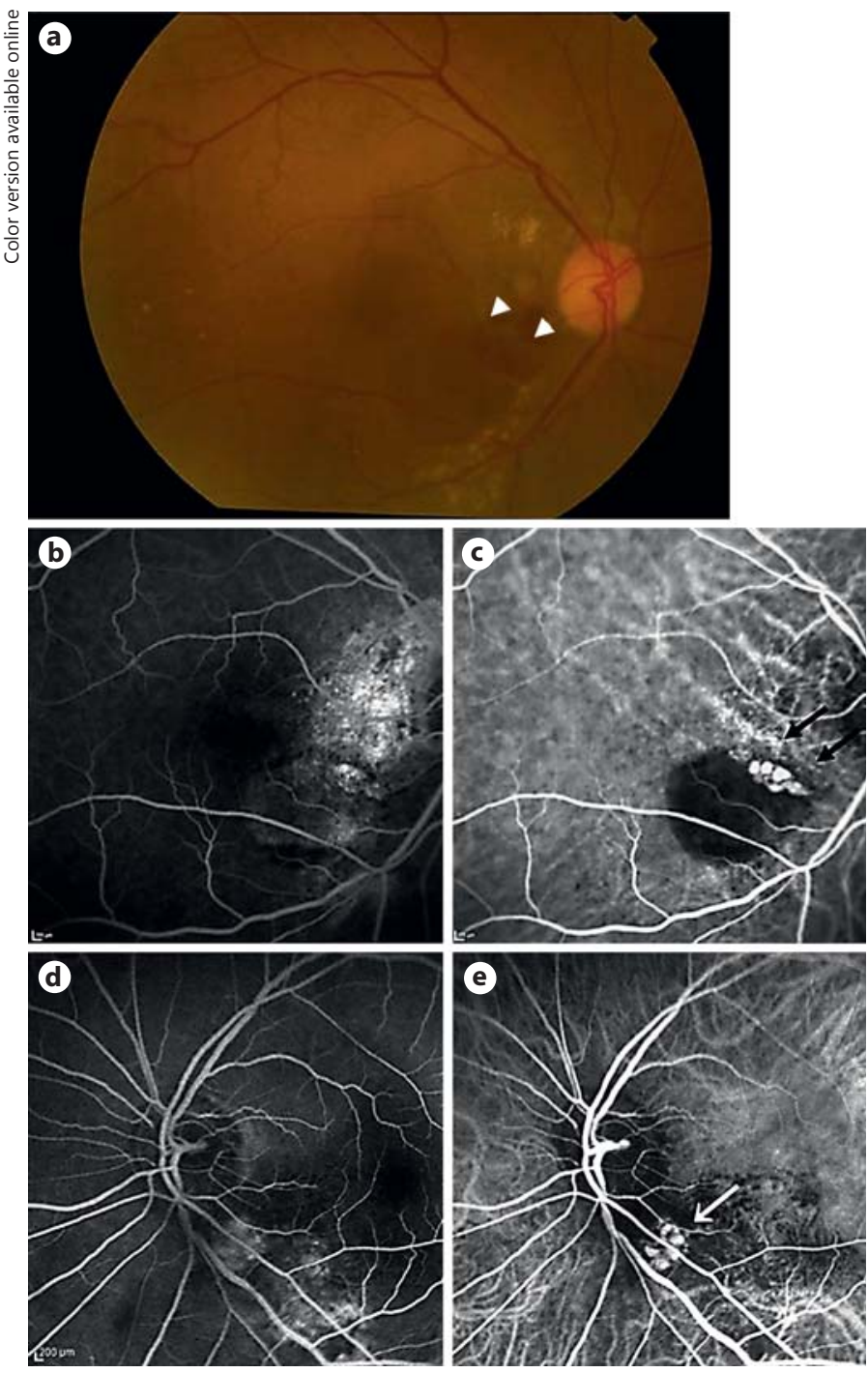

Fig. 2. Fundus photography, fluorescein angiography and indocyanine green angiography images of peripapillary PCV. a Orange-red lesions (arrowheads) at the margin and inside serous PED are found in the peripapillary area. b Window defect and staining of retinal pigment epithelium are found by the optic nerve head in fluorescein angiography. Note that the fovea is not involved. c A cluster of polypoidal lesions (black arrows) is found in indocyanine green angiography. d, e Another case of peripapillary PCV. Clustered polypoidal lesions (white arrow) are found at the lower position of the optic nerve head.

ings at the initial visit may vary depending on when the patients visit the hospital. Although Uyama et al. [12] reported that about $83 \%$ ( 10 out of 12 cases) of PCV patients showed SRD at the first visit, Sho et al. [11] reported that about $52 \%$ of PCV patients showed SRD. In a recent report, Bessho et al. [13] observed SRD in $91 \%$ of the pa- tients, and subretinal hemorrhage in $62 \%$ of the patients with PCV at the first examination. Previous studies have reported that polyp lesions are mostly present at the margin and inside the serosanguinous PED, which may present as a 'notch sign' between the PED, including polyp lesions and connecting PED, which includes abnormal network vessels [11]. Two previous studies also reported that subretinal fibrinous material on the PED is often observed in PCV $[44,45]$. Retinal pigment epithelium (RPE) abnormalities (i.e. hyperplasia, atrophy) are frequently found overlying and around the lesions $[11,13]$. Microrips of the RPE and RPE tears could be found at the margins of the PEDs $[46,47]$. In some cases, multiple PEDs may span widely at the posterior pole of the retina, or more than 2 independent lesions could be found (i.e. one lesion at the macula and the other at the nasal retina) [48]. However, unlike tAMD, cases with no exudative changes are relatively common in PCV.

The visual acuity (VA) at the initial visit may vary depending on the degree of the exudative change. Those cases without subretinal hemorrhage and with no or slight SRD have good VA, whereas VA in those cases with severe exudative changes may be affected. However, the mean VA in PCV patients was generally better than in tAMD at baseline [49]. This is likely because PCV lesions remain under the RPE in the early stages, while tAMD occasionally develops $\mathrm{CNV}$ in the subretinal space (the so-called type $2 \mathrm{CNV}$ ), which may affect the sensory retina directly.

\section{Angiographic Imaging}

Unfortunately, fluorescein angiography (FA) is not an optimal tool to make a diagnosis of PCV, since FA is not sufficient to visualize the structures in the inner choroidal space where PCV likely exists. However, a 'window defect' reflecting RPE atrophy is often observed, and the underlying polypoidal lesions may be found as 'hyperfluorescent spots' by FA in certain PCV cases [28]. Subretinal fibrinous material, if it exists, can be observed as an expanding fluorescent leakage that may simulate the classic lesion of tAMD found by FA $[44,45]$. This appearance might be termed a 'pseudoclassic CNV lesion', which is a characteristic of PCV (fig. 3).

In ICGA, PCV is typically characterized by distinct forms of choroidal vascular abnormalities, including characteristic polypoidal lesions with or without branching vascular networks (BVNs) of choroidal origin [50]. As described above, polyp lesions are mostly present at the mar- 
Fig. 3. Fundus photography, FA, ICGA and optical coherence tomography images of PCV which simulates tAMD. a A fibrinous subfoveal lesion (arrowheads) with subretinal hemorrhage is found in the juxtafoveal region. b A solitary polyp lesion (arrow) is found in ICGA. c-e A presentation similar to predominantly classic $\mathrm{CNV}$ is found in FA, although there is no true classic lesion. c-e represent the image at 1,5 and $10 \mathrm{~min}$, respectively. This manifestation could be called 'pseudoclassic CNV appearance'. f, g Subretinal fibrinous material (arrows) occupying the subretinal space is found by optical coherence tomography.
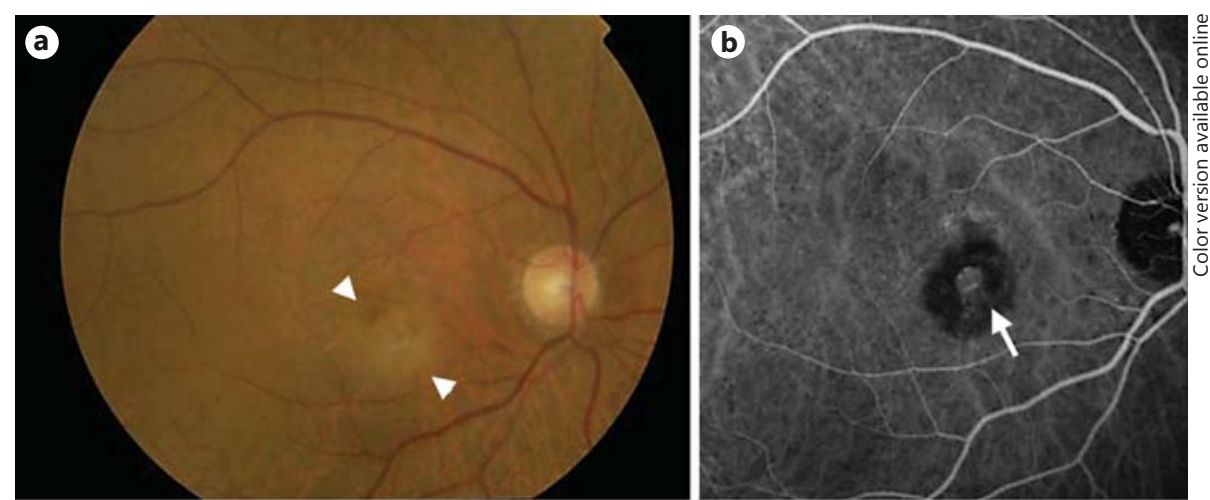
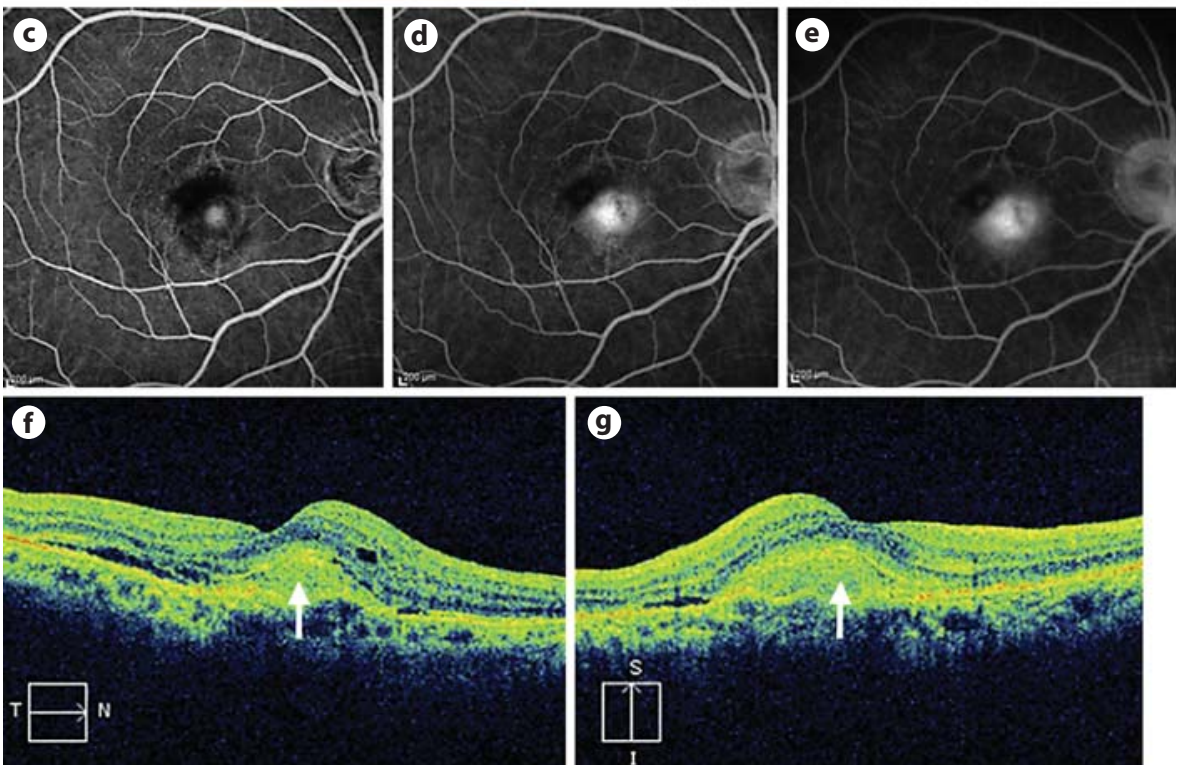

gin and inside the PED, which may cause a 'notch sign' between the PED, including polyp lesions and connecting PED, which includes the BVN. Clustered grape-like polypoidal lesions on ICGA were observed frequently (25$67 \%$ ) in Asian populations $[12,13,48]$. It is very unique for PCV that some cases show pulsations of the polypoidal lesions in the early phase of ICGA [50-52]. Dilatation of choroidal vessels found in the early and middle phases of ICGA is another unique feature of PCV (fig. 4). Choroidal vascular hyperpermeability is often found in PCV by ICGA in the late phases, and is likely due to the staining of fibrinous materials which exist around the dilated choroidal vessels [53-55]. PCV cases show wide variation in their size, and the features of the BVN and polypoidal lesions. The Japanese Study Group of Polypoidal Choroidal Vasculopathy proposed that PCV with only BVN and no apparent polypoidal lesions may exist, and those cases are termed 'suspected of PCV' [43]. However, those cases are often difficult to distinguish from tAMD. The variations of PCV in its presentation may be only due to the stage of the disease (more progressed disease should have larger lesions) [56], but evidence is accumulating which supports the existence of subtypes in PCV.

Recent studies have described the subclassification of PCV regarding the presence or absence of BVN (as feeder vessels for the polyp lesions) found by ICGA [57-59]. Thus, PCV with apparent BVN is called 'type 1 PCV' or 'polypoidal CNV', whereas the one with no or only faint BVN is called 'type 2 PCV' or 'typical PCV' (fig. 5). The presence or absence of BVN can usually be determined within $1 \mathrm{~min}$ starting from the injection of ICGA, but some cases are difficult to classify. Recent studies demonstrated that these 2 angiographic subtypes of PCV showed differences in their clinical course, genetic susceptibility and response to therapy. Type $1 \mathrm{PCV}$ usually has larger lesion sizes due to the larger and more distinct BVN, 
Fig. 4. Corresponding images of FA, ICGA and optical coherence tomography in a PCV case. a A window defect is observed in the early phase ( $1 \mathrm{~min}$ ) of FA. b Polypoidal lesions (arrows) present inside PED are found in ICGA. BVN vessels are found (open arrowheads) in the area which shows the window defect in FA. Choroidal vessels are dilated (filled arrowheads). c Infrared image captured by optical coherence tomography which shows the tomographic section line of $\mathbf{d}$. $\mathbf{d}$ A sharp-edged PED and connected lower PED exhibit the tomographic notch sign (long thin arrow). Polypoidal lesions (asterisk) are attached to the back surface of the higher PED, and a $\mathrm{BVN}$ exists in the lower PED which is recognized as 'double layer sign' (open arrowheads). Subfoveal choroidal thickness is remarkably increased (bidirectional arrows).
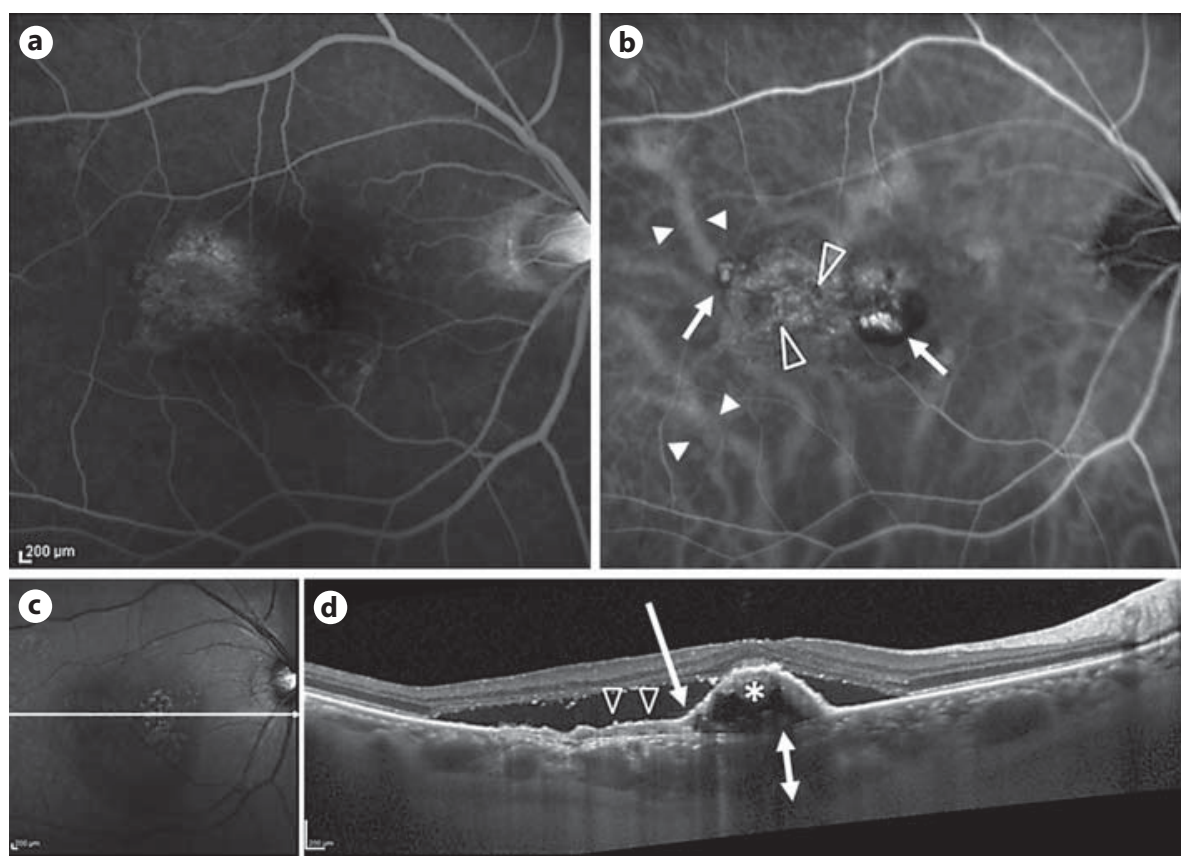

smaller polyp size on ICGA, smaller choroidal thickness [57-59] and lower response to photodynamic therapy (PDT) as compared to type $2 \mathrm{PCV}$ [60].

\section{Optical Coherence Tomography}

In most PCV cases, optical coherence tomography (OCT) revealed a sharply elevated PED with/without connecting lower PEDs, which may cause the so-called 'tomographic notch sign' (fig. 4) [61]. Polypoidal lesions are likely to attach to the back surface of higher PEDs, and BVN present in the lower PED can be recognized as the 'double layer sign' by high-resolution OCT. This sign represents the BVN invading into the space between the RPE and Bruch's membrane, which is commonly found in CNV due to tAMD. Because CNV in tAMD is thought to pass through Bruch's membrane and grow under (and often over) the RPE layer, at least 1 broken site of Bruch's membrane should be detected. Using OCT, suspected broken sites of Bruch's membrane are often observed in type 1 $\mathrm{PCV}$ at the origin of the BVN [57]. These findings suggest that PCV is a type of CNV. However, the 'double layer sign' found in PCV may not necessarily mean the isolation of the RPE from Bruch's membrane. A recent study reported that the isolation between Bruch's membrane and the inner choroidal surface also exhibits a 'double layer
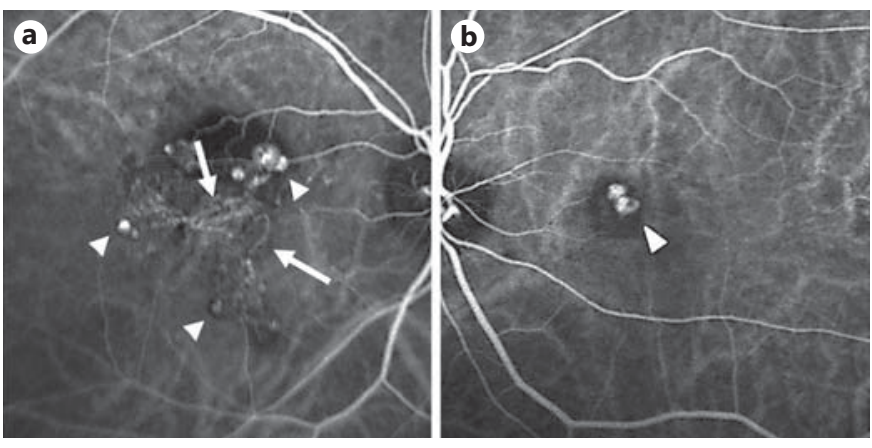

Fig. 5. Two different angiographic subtypes of PCV. Images are obtained in the early phase (up to $1 \mathrm{~min}$ ) of ICGA. a Type $1 \mathrm{PCV}$ shows polypoidal lesions (arrowheads) with clear BVNs (arrows). b Type 2 PCV shows polypoidal lesions (arrowhead) without or faint vascular networks.

sign', which means that the BVN of the PCV may remain under Bruch's membrane with polypoidal lesions [57] (fig. 6). An increase in central choroidal thickness is frequently observed by high-resolution OCT with enhanceddepth imaging or by high-permeability OCT $[62,63]$ (fig. 4). Several studies reported that the mean choroidal thickness of PCV patients was significantly larger than that of normal subjects $[62,64-66]$. This increase in choroidal thickness was reported to be associated with increased oc- 

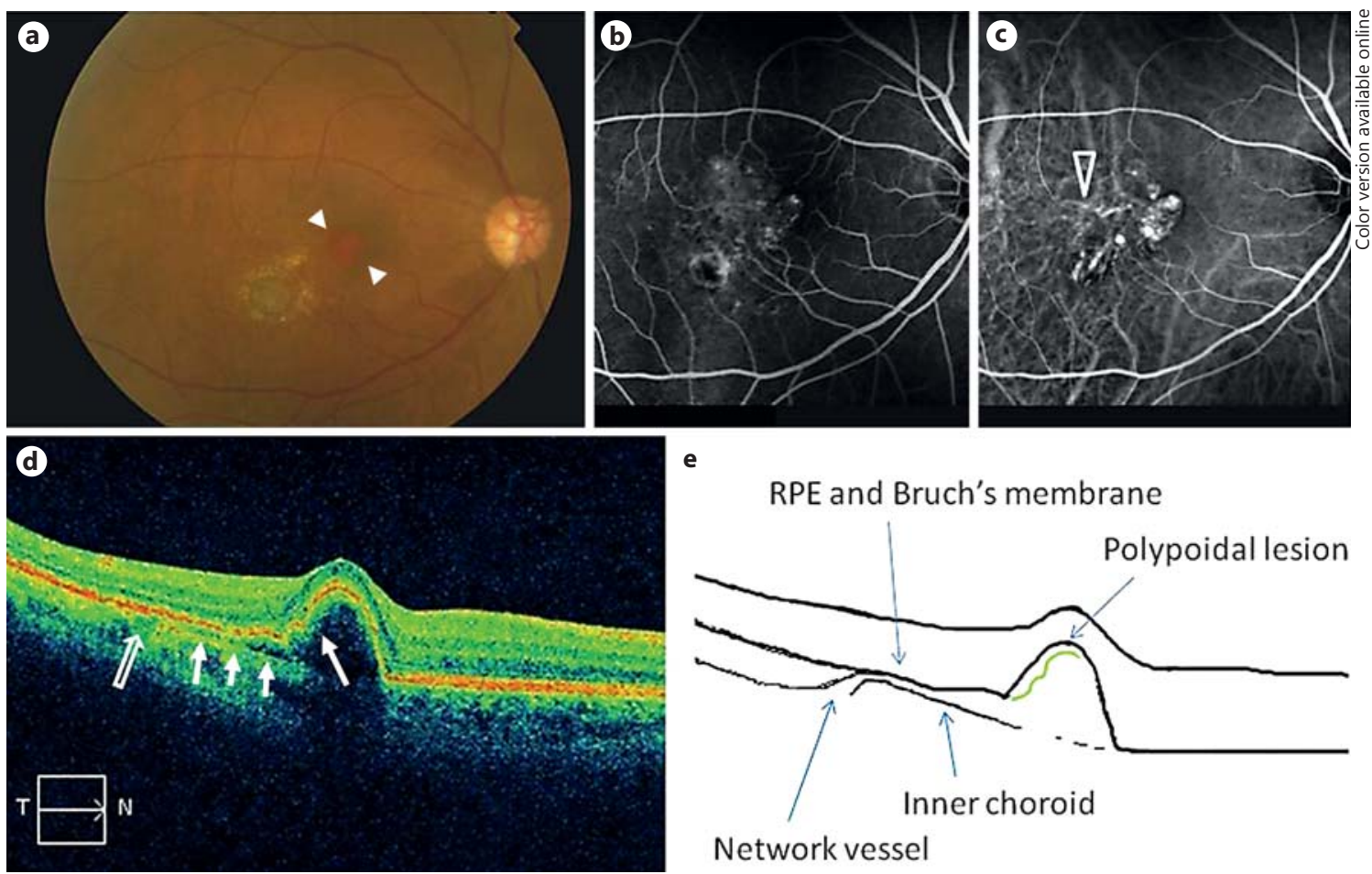

Fig. 6. Fundus photography, FA, ICGA and OCT images of type 2 PCV. a An orange-red lesion (arrowheads) is found at the fovea. $\mathbf{b}$ An occult with no classic lesion is observed by FA. c Distinct polypoidal lesions with a faint network vessel (open arrowhead) are found in ICGA. d The origin of a network vessel is indicated with an open arrow. The suspected isolation between Bruch's membrane and the inner choroidal surface (short arrows) exhibits the 'double layer sign' in OCT. Polypoidal lesions (long arrow) are located on the back surface of the detached RPE with underlying Bruch's membrane. e Explanatory illustration of $\mathbf{d}$.

ular perfusion pressure and an engorgement of the vortex vein $[67,68]$. It is interesting that central serous chorioretinopathy, known as a risk factor of PCV, also shows a remarkable increase in choroidal thickness $[62,64]$.

\section{Fundus Autofluorescence}

Fundus autofluorescence studies performed for PCV have been recently reported. In the affected eyes with PCV, confluent hypoautofluorescence at the polypoidal lesions surrounded by a hyperautofluorescent ring was seen in $80.4 \%$ of PCV cases, and granular hypoautofluorescence at the BVN was seen in $98.9 \%$ of PCV cases. In addition, $42.4 \%$ of eyes with PCV showed hypoautofluorescence outside the macular area. In the unaffected fellow eyes, hypoautofluorescence was observed inside the macular area (58.1\%) and in the entire fundus autofluorescence image $(62.8 \%)$ in patients with $\operatorname{PCV}[69,70]$.

\section{Histopathology}

Histopathological studies of PCV using human specimens were conducted by obtaining subretinal tissues during vitreoretinal surgeries $[55,71-75]$. One report noted that polypoidal structures were located within Bruch's space. They were composed of clusters of dilated, thinwalled blood vessels surrounded by macrophages and fibrin material [71]. Kuroiwa et al. [72] reported that 4 of their 5 cases demonstrated large choroidal arterioles with an inner elastic layer; disruption of the inner elastic layer and arteriosclerotic changes of the vessels were identified. Increased deposition of basement membrane-like material, together with collagen fibers, arterioles and venules, can be found in excised specimens from patients with PCV, and arteriosclerosis was an important pathological feature [72]. Another histopathological examination revealed that the specimen consisted of a degenerated RPEBruch's membrane-choriocapillaris complex and an in- 
ner choroid. A tortuous, unusually dilated venule was present adjacent to an arteriole with marked sclerotic changes, appearing to form an arteriovenous crossing. These vessels seemed to represent native inner choroidal vessels, and had hemorrhage per diapedesis. Blood cells and fibrin filled the lumina of these vessels, and accumulated in the extravascular spaces, thus indicating vascular stasis [55]. Hyperpermeability and hemorrhage due to stasis of a dilated venule and an arteriole involved by sclerosis at the site where they crossed in the inner choroid might cause edema and degeneration of the tissue. A voluminous accumulation of blood cells and fibrin might generate an elevation of tissue pressure sufficient to displace the weakened lesion anteriorly. These results suggest that the polypoidal vessels in this case represent an abnormality in the inner choroidal vasculature. Another study reported positive immunohistochemical staining for vascular endothelial growth factor (VEGF) in the RPE and the vascular endothelial cells in the specimen, which suggested that the fibrovascular complex was a subretinal CNV [73]. In a recent study, hyalinization of the choroidal vessels and a massive exudation of fibrin and blood plasma with a change in the arteriosclerosis were observed in all of the specimens from PCV lesions. Some blood vessels were located above the RPE in 2 of the 5 eyes analyzed [74]. Immunohistochemically, CD68-positive cells were detected around the hyalinized vessels. There were no smooth muscle actin-positive cells in the vessels in the PCV. CD34 staining showed endothelial discontinuity. Vascular endothelial cells within the PCV specimens were immunonegative for VEGF. Hypoxia inducible factor-1-immunopositive inflammatory cells were located in the stroma of specimens [74].

\section{Genetic Factors}

The molecular mechanisms responsible for the onset of disease, for the outcomes of the natural course, or any interventions, are not understood in PCV. Genetic association analysis was thought to be a useful tool to find those molecules which may be involved in the pathogenesis of this disease. For example, genetic variants in the complement factor $\mathrm{H}(\mathrm{CFH})$ gene on chromosome 1q32 [75-79] and in 2 tightly linked genes, age-related maculopathy susceptibility 2 (ARMS2), also known as LOC387715, and high-temperature requirement factor A1 (HTRA1) on 10q26 [80-83] are well known as major contributors to AMD. In particular, the single-nucleotide polymorphism (SNP) at rs1061170 (coding variant

Polypoidal Choroidal Vasculopathy
$\mathrm{Y} 402 \mathrm{H}$ ) in the $\mathrm{CFH}$ gene is presumed to have functional consequences consistent with AMD pathology [84]. However, the $C F H \mathrm{Y} 402 \mathrm{H}$ variant shows apparent ethnic differences in its association with AMD because of the frequency of the risk allele ( $\mathrm{C}$ allele); the risk allele frequency is 0.38 in Caucasians in the HapMap database [85], but it is 0.057 in the Japanese population and 0.067 in the Chinese population. Hence, $C F H \mathrm{Y} 402 \mathrm{H}$ shows a strong association with AMD in Caucasians, but it was difficult to detect a positive association with Asian AMD cases owing to a limitation in statistical power [86-89]. Recently, large population studies and meta-analyses came to identify the $C F H \mathrm{Y} 402 \mathrm{H}$ variant as a significant genetic risk factor in Asian AMD [20,90], although the susceptibility conferred by the $\mathrm{Y} 402 \mathrm{H}$ variant may not translate across ethnic lines. However, other multiple $\mathrm{CFH}$ variants have been shown to be associated with AMD in Asians [89, 91-93]. In particular, the CFH I62V variant was significantly associated with AMD (allelic $\mathrm{OR}=1.85,95 \% \mathrm{CI}=1.63-2.09)$ in a meta-analysis of Asian cohorts although no significant association of this SNP was established with AMD in Caucasian populations [91]. These reports suggested that variations in the $\mathrm{CFH}$ gene universally influence AMD susceptibility, but causal SNPs in the $C F H$ region may vary among races.

Although limited information is available on the genetic basis of PCV, several studies demonstrated how genetics play an important role in the pathogenesis of PCV. The 2 major AMD susceptibility loci (CFH and ARMS2/ HTRA 1) have been shown to influence the risk of PCV [18-20, 94-100]. In particular, SNPs in the ARMS2/ HTRA1 locus, rs10490924 (A69S) and rs11200638, are significantly associated with PCV [18, 20, 22-24]. Moreover, recent transgenic mouse studies demonstrated that the overexpression of HTRA1 displayed the cardinal features of PCV, including branching networks of choroidal vessels, polypoidal lesions and severe degeneration of the elastic laminae and tunica media of the choroidal vessels [101, 102]. However, all genetic association studies showed a weaker association of ARMS2/HTRA1 with PCV than with tAMD, although the reasons were unknown (table 1). Those results raised the question whether other susceptible genes which are specific for PCV pathogenesis may exist. A previous report showed that coding variants of the elastin gene (rs2301995 and rs2856728) were associated with PCV, but not with tAMD [103]. However, two subsequent reports with larger cohorts showed the opposite results: the elastin gene polymorphism was associated with tAMD but not with PCV $[22,104]$, which made the association of elastin gene vari- 
Table 1. Genetic association analysis studies for ARMS2 rs10490924 (A69S) in tAMD and PCV

\begin{tabular}{|c|c|c|c|c|c|c|c|c|}
\hline \multirow[t]{2}{*}{ Study } & \multirow[t]{2}{*}{ Year } & \multirow[t]{2}{*}{ Ethnicity } & \multicolumn{3}{|c|}{ Number of genotypes (GG/GT/TT) } & \multicolumn{3}{|c|}{ Risk allele frequency } \\
\hline & & & tAMD & PCV & control & tAMD & PCV & control \\
\hline Sakurada et al. [109] & 2008 & Japanese & NA & $15 / 49 / 45$ & $39 / 32 / 14$ & NA & 0.64 & 0.35 \\
\hline Lee et al. [102] & 2008 & Chinese & NA & $17 / 30 / 25$ & $33 / 48 / 12$ & NA & 0.56 & 0.39 \\
\hline Gotoh et al. [19] & 2009 & Japanese & $18 / 30 / 52$ & $18 / 50 / 32$ & $85 / 84 / 20$ & 0.67 & 0.57 & 0.33 \\
\hline Hayashi et al. [20] & 2010 & Japanese & $67 / 155 / 183$ & $122 / 216 / 171$ & $502 / 638 / 196$ & 0.64 & 0.55 & 0.39 \\
\hline Fuse et al. [21] & 2011 & Japanese & $6 / 20 / 24$ & $22 / 20 / 18$ & $64 / 58 / 16$ & 0.68 & 0.47 & 0.33 \\
\hline Tanaka et al. [22] & 2011 & Japanese & $46 / 81 / 126$ & $94 / 162 / 125$ & $99 / 142 / 36$ & 0.66 & 0.54 & 0.39 \\
\hline Yanagisawa et al. [23] & 2011 & Japanese & $26 / 81 / 74$ & $42 / 77 / 79$ & $79 / 94 / 30$ & 0.63 & 0.59 & 0.38 \\
\hline Liang et al. [24] & 2012 & Chinese & $15 / 46 / 90$ & $23 / 79 / 60$ & $90 / 117 / 40$ & 0.75 & 0.61 & 0.40 \\
\hline
\end{tabular}

NA $=$ Not assessed

ants with tAMD and PCV inconclusive. Those results might have occurred due to statistical type 1 and type 2 errors, but it is also possible that PCV is not a genetically homogeneous pathology. Another study reported that a missense variant at rs5882 in the cholesteryl ester transfer protein gene, a key regulator of high-density lipoprotein metabolism, was significantly associated with PCV ( $\mathrm{p}=$ $2.73 \times 10^{-4}$ ), although it was not associated with tAMD [25]. The rs5882 GG genotype had a 3.53-fold $(95 \% \mathrm{CI}=$ 1.93-6.45) increased risk for PCV, and conferred a significantly lower serum high-density lipoprotein cholesterol level in PCV patients than the AA genotype ( $\mathrm{p}=$ 0.048). On chromosome 9p21, which is well known to be associated with coronary artery disease and type 2 diabetes, rs 10757278 was significantly associated with PCV (risk allele: A, allelic $\mathrm{p}=0.014$; $\mathrm{OR}=1.44 ; 95 \% \mathrm{CI}=1.08$ 1.94), but was not associated with tAMD [105].

Recently, two studies demonstrated a difference in the association of the rs10490924 (A69S) variant in ARMS2 between the two angiographic phenotypes of PCV, type 1 PCV and type 2 PCV $[27,58]$ (fig. 5). In those studies, no association of the ARMS2 A69S polymorphism with type 2 PCV was detected, whereas type 1 PCV showed a strong association with the ARMS2 A69S variant. Since the ARMS2 polymorphism is widely known to associate with $A M D$, their report indicates the existence of heterogenic susceptibility within PCV phenotypes, which may contribute to the different characteristics of PCV versus tAMD. This dissociation between the two angiographic phenotypes might suggest a correlation of ARMS2 with the formation of the BVN in PCV. In addition, this genetic heterogeneity in PCV may be a reason for the lower association of ARMS2/HTRA1 with PCV, including both phenotypes (types 1 and 2), than with tAMD.

\section{Natural Course}

Previous studies have reported that the natural course of PCV is favorable, since it often shows spontaneous regression $[10-12,28]$. However, on the other hand, it often causes severe hemorrhagic and exudative changes that result in a poor visual prognosis $[12,13]$. The clinical risk factors for a poor prognosis in PCV have been previously evaluated [11-13]. Bessho et al. [13] investigated the natural course of PCV in terms of the changes in the bestcorrected VA (BCVA) after 12 months of observation, and found that the mean BCVA of PCV patients worsened significantly over the natural course. The clustered polypoidal choroidal lesions detected by ICGA were associated with a poor prognosis over the natural course. In this report, over $20 \%$ of PCV patients gained VAs of more than $0.2 \log M A R$, whereas about $50 \%$ of the patients lost their VA by more than $0.2 \log$ MAR during the 12 months after the initial visit. The presence of serous PED is a suspected risk factor, whereas the presence of subretinal fibrinous material is a possible beneficial factor for the 12 -month BCVA in PCV patients. Since polyp lesions are mostly present at the margin and inside the PED, and serous PED suggests strong infiltrating activity of the PCV [106], the accelerated infiltration from the polyp lesions into the subretinal pigment epithelial space may increase the tension on the PED flap, and thus cause PED microrips followed by acute decompression of the PED and increased blood flow in the polyp lesions. This then results in the rupture of these polyp lesions, and acute severe hemorrhage. In fact, PCV is often associated with systemic hypertension [38-40]. Subretinal fibrinous material, often observed on the PED in PCV patients, may be a beneficial factor for the visual prognosis over the natural 
course or after treatment $[13,44,45]$. Although the detailed mechanism of how this subretinal fibrinous material contributes to a better prognosis for PCV over its natural course is unknown, the involvement of an acute inflammatory pathway to produce this fibrinous material was suspected in certain cases of PCV [74, 107, 108], which often resolve spontaneously like common inflammatory conditions.

The clustered lesions found by ICGA induced a disadvantage to the visual outcome in PCV $[12,13]$. As a genetic risk factor, the risk alleles at rs10490924 and rs 11200638 in the ARMS2/HTRA 1 locus were reported to be significantly associated with a larger lesion size, a higher risk of vitreous hemorrhage, an earlier onset and a bilateral involvement, as compared to nonrisk allele holders in PCV cases [19, 109-111].

\section{Response to Treatment}

\section{Photodynamic Therapy}

Evidence is accumulating that PCV shows a better response to PDT than tAMD $[14,15,112]$. Most studies reported that the mean posttreatment VA was improved in PCV over a short-term follow-up (up to 1 year). In particular, most polypoidal lesions regressed by PDT whereas the BVN remains after PDT [113-116]. A recent multicenter randomized controlled trial revealed that polyp lesions disappeared in more than $70 \%$ of the PCV cases within 6 months after PDT [117]. However, several reports suggested some heterogeneity in the response to PDT among PCV patients [15, 52]. Tamura et al. [45] reported better outcomes for PCV cases with subretinal fibrinous material adjacent to the polypoidal lesions treated with PDT. In accordance with the literature, PCV cases with grape-shaped polyp lesions showed poorer outcomes than other PCV cases. In view of the angiographic subtypes of PCV, type $1 \mathrm{PCV}$ is considered to be more refractory to PDT than type $2 \mathrm{PCV}$ [60]. Although the mean VA was improved and maintained up to 12 months after PDT in most reports [14, 15, 112-119], longer observational studies revealed that the merit of therapy was reduced 12 months after the initial PDT, mainly due to recurrences of the lesions [14, 120-122]. Consequently, the improvement in the mean VA of the PCV patients was not significant anymore 30-36 months after the initial PDT $[14,121,122]$. Moreover, it could be below the baseline value 5 years after the treatment [123-125]. Persistent BVN may be the origin of new polypoidal lesions [126]. In a recent prospective cohort study, 56 out of 139 eyes (40\%) in the tAMD cases and 52 out of 107 eyes (49\%) in the PCV cases were recurrent during the 60 months of follow-up after the initial PDT [123]. In particular, 44 eyes (32\%) in the tAMD and 27 eyes (25\%) in the PCV cases were recurrent within 12 months after the initial resolution of the lesions obtained by PDT. The mean recurrence period during the 60 months of followup was $15.7 \pm 13.5$ months (mean \pm SD) in the PCV group, which was significantly longer than in the tAMD group (8.6 \pm 9.3 months). The mean VA was maintained for 60 months in the tAMD and PCV patients who showed no recurrence of their lesions.

Recently, genetic variants in the $\mathrm{CFH}$ gene have been tested to explain the response to PDT. In particular, the $\mathrm{Y} 402 \mathrm{H}$ coding variant (rs1061170) in $\mathrm{CFH}$ is presumed to have functional consequences consistent with AMD pathology [84], and most studies were performed to determine whether $\mathrm{CFH} \mathrm{Y} 402 \mathrm{H}$ correlates with the outcome of PDT [127-131]. In tAMD, Brantley et al. [129] reported an association of the $C F H \mathrm{Y} 402 \mathrm{H}$ variant with the visual outcome after PDT. In that study, the $\mathrm{C}$ allele was beneficial for the patients. Goverdhan et al. [131] also reported the positive association of $C F H \mathrm{Y} 402 \mathrm{H}$ with the outcome of PDT in tAMD, but discovered the $\mathrm{C}$ allele as the risk allele for a better VA. On the other hand, other studies failed to demonstrate any association of this variant with the outcome of PDT [127, 128, 130]. In PCV cases, one study demonstrated that the SNPs rs $1061170(\mathrm{Y} 402 \mathrm{H})$ and $\mathrm{rs} 1410996$ in the CFH region were significantly associated with an anatomical response to PDT [132]. Two studies found that the genotype at rs10490924 (A69S) in ARMS2 was significantly associated with the lesion size in PCV patients, as well as the visual outcome in tAMD and PCV patients 12 months after their first PDT $[110,133]$. Therefore, patients with more $\mathrm{G}$ alleles at rs10490924 showed better BCVA values until 12 months after their first PDT. Nakata et al. [134] reported that a variant at rs12603825 in the pigment epithelium-derived factor gene was associated with the recurrence-free period, and our own study revealed a significant association of the SNP at rs3173798 in the CD36 gene with the visual outcome of PDT in a dominant model. The presence of the $\mathrm{C}$ allele in rs3173798 was significantly associated with a poor response to PDT after multivariate logistic regression analysis with clinical pre-PDT parameters. The mean BCVA in the group with the TT genotype of rs3173798 was significantly improved over the 12 months of follow-up after the initial PDT [135]. 
Table 2. CFH Y402H variants and their influence on the outcome of anti-VEGF therapy

\begin{tabular}{|c|c|c|c|c|}
\hline Authors & $\begin{array}{l}\text { Anti-VEGF } \\
\text { agent }\end{array}$ & Cases, $\mathrm{n}$ & Main outcome measures & $\begin{array}{l}\text { Genotypes with } \\
\text { beneficial effects }\end{array}$ \\
\hline Smailhodzic et al. [155] & Ranibizumab & 420 & Posttreatment VA at 3 months (logMAR) & $\mathrm{TT}>\mathrm{CC}$ \\
\hline $\begin{array}{l}\text { Kloeckener-Gruissem } \\
\text { et al. [151] }\end{array}$ & Ranibizumab & $\begin{array}{l}243 \\
(63 / 63 \text { eyes })\end{array}$ & $\begin{array}{l}\text { Change in VA at } 12 \text { months from baseline } \\
\text { (upper } 25 \% \text { /lower } 25 \% \text { ) }\end{array}$ & $\mathrm{TT}, \mathrm{CT}>\mathrm{CC}$ \\
\hline Lee et al. [153] & Ranibizumab & 156 & Number of retreatments during 9 months & $\mathrm{TT}>\mathrm{CC}$ \\
\hline Orlin et al. [150] & $\begin{array}{l}\text { Ranibizumab, } \\
\text { bevacizumab }\end{array}$ & 150 & Posttreatment VA (deterioration $+/-)$ & NS \\
\hline McKibbin et al. [152] & Ranibizumab & 104 & $\begin{array}{l}\text { Change in VA at } 6 \text { months from baseline } \\
\text { (more than } 5 \text {-letter improvements }+/- \text { ) }\end{array}$ & $\mathrm{CC}, \mathrm{CT}>\mathrm{TT}$ \\
\hline Chang et al. [158] & Ranibizumab & 102 & Posttreatment VA at 3 and 6 months (logMAR) & $\begin{array}{l}\mathrm{CC}>\mathrm{CT}>\mathrm{TT} \\
\text { (tendency, NS) }\end{array}$ \\
\hline Yamashiro et al. [147] & Ranibizumab & 75 & Posttreatment VA at 3 and 12 months (logMAR) & NS \\
\hline
\end{tabular}

Table 3. SNPs in the VEGF-A region and the effects on the outcome of anti-VEGF therapy

\begin{tabular}{lllll}
\hline SNP ID & Location & $\begin{array}{l}\text { Major/minor } \\
\text { allele }\end{array}$ & Main outcome measures & $\begin{array}{l}\text { Genotypes with } \\
\text { beneficial effects }\end{array}$ \\
\hline rs1413711 & Intron 1 & C/T & $\begin{array}{l}\text { Change in VA at 6 months from baseline } \\
\text { (more than 5-letter improvements +/-) }\end{array}$ & CC, CT > TT [152] \\
\hline rs833069 & Intron 2 & A/G & $\begin{array}{l}\text { Change in CRT at 3 months from baseline } \\
\text { Change in VA (logMAR) at 3 months from baseline }\end{array}$ & GG $>$ AA [158] \\
\hline rs3025000 & Intron 3 & C/T & Change in ETDRS letters at 6 months from baseline & CC < CT, TT [159] \\
\hline rs699947 & Promoter & C/A & $\begin{array}{l}\text { Change in VA (logMAR) at 3 months from baseline } \\
\text { Change in VA (logMAR) at 12 months from baseline }\end{array}$ & $\begin{array}{l}\text { NS [155] } \\
\text { NS [160] }\end{array}$ \\
\hline rs699946 & Promoter & G/A & Change in VA (logMAR) at 12 months from baseline & GG $>$ GA $>$ AA [160] \\
\hline
\end{tabular}

CRT = Central retinal thickness; NS = not significant; ETDRS = Early Treatment Diabetic Retinopathy Study.

\section{Anti-VEGF Therapy}

The intravitreal injection of anti-VEGF agents is currently the primary treatment for exudative AMD. Studies from Western countries have reported significantly better visual outcomes with monthly intravitreal injections of ranibizumab (IVR) than PDT in exudative AMD patients $[136,137]$, but these studies did not distinguish between the phenotypes of AMD, and the effects of antiVEGF therapy for PCV may differ from those for tAMD.
Overall, the effects of IVR monotherapy against PCV are currently contentious, and no consensus has been reached to date. Some studies reported that the polypoidal lesions of PCV were barely resolved by anti-VEGF monotherapy, which might explain the limited efficacy of IVR against PCV [138-140]. However, Song et al. [141] reported that IVR without PDT for PCV in Korean patients resulted in significant visual and anatomical improvements over a 1-year follow-up period, and other 
reports suggested that the disappearance of the polypoidal lesions occurred at a high rate in PCV cases after anti-VEGF monotherapy $[74,142,143]$. A recent review suggested an overall improvement of the VA of PCV patients using IVR [144], and a most recent multicenter randomized controlled trial (LAPTOP study) revealed that IVR monotherapy achieved a significantly better visual prognosis than PDT monotherapy in PCV patients [145]. However, Matsumiya et al. [16, 17] reported that the degree of improvement in the VA in PCV patients was lower than that of tAMD patients treated by antiVEGF monotherapy. Some reports demonstrated that several pretreatment factors influenced the outcome of IVR $[16,17,146]$, which might be useful to predict the visual and anatomical consequences for PCV patients who undergo IVR.

Although very little has been studied about the genetic factors associated with the outcome of IVR in PCV patients [147], a number of recent studies assessed the possible genetic factors associated with the outcome of IVR in tAMD patients [147-160]. Most studies focused on the SNPs in the CFH, ARMS2 and VEGF- $A$ genes, since these genes were reported to be associated with the pathogenesis of exudative AMD, but a consistent conclusion has not been made to date (tables 2, 3). In particular, CFH $\mathrm{Y} 402 \mathrm{H}$ was the most studied SNP and many reports demonstrated that the $\mathrm{C}$ allele in $\mathrm{CFH} \mathrm{Y} 402 \mathrm{H}$ was associated with the reduced response to anti-VEGF therapy [151, 154, 155]. Since the C allele in $C F H \mathrm{Y} 402 \mathrm{H}$ is known to be a risk allele for the incidence of exudative AMD, C allele-rich cases likely have more active lesions than the others, and hence those cases are likely more refractory to the treatment. A recent meta-analysis demonstrated the association of $C F H \mathrm{Y} 402 \mathrm{H}$ with the visual outcome of IVR in Caucasians (the CC genotype showed a decreased response to anti-VEGF therapy compared to the TT genotype) [148]. However, more recent reports described that the $\mathrm{C}$ allele was beneficial for the posttreatment BCVA in British and Korean populations over shorter (3 and 6 months) follow-up periods $[152,158]$. The risk/ benefit effects of $\mathrm{CFH} \mathrm{Y} 402 \mathrm{H}$ regarding the treatment outcome might be changed by the proportion of AMD phenotypes at baseline or by the duration of the follow-up period. Moreover, the association of $\mathrm{CFH} \mathrm{Y} 402 \mathrm{H}$ with the outcome of IVR might be different between Caucasians and Asians, since the frequency of the $\mathrm{C}$ allele is very low in Asian populations [90]. Although Chang et al. [158] and Yamashiro et al. [147] reported a relatively better visual outcome (though not significantly better) in the Crich genotypes than the others for $\mathrm{CFH} \mathrm{Y} 402 \mathrm{H}$ in the
Asian populations, additional meta-analyses will be required to conclude the association of $C F H \mathrm{Y} 402 \mathrm{H}$ with the visual outcome of IVR in Asians, particularly in PCV cases.

\section{Combination Therapy}

Recently, a multicenter randomized controlled trial (EVEREST study) was conducted to compare the effects of PDT monotherapy, IVR monotherapy and their combination (PDT + IVR) in patients with PCV. It reported that all therapies resulted in improvements of the patients' VAs 6 months after treatment [117]. In addition, PDT monotherapy and combination therapy achieved a significantly higher proportion of patients with complete polyp regression (more than $70 \%$ ) at 6 months than IVR monotherapy (less than 30\%). Similar results were reported in other studies with different populations [113, $116,139,143,146,161]$. Considering the results from recent publications, combination therapy is likely the most effective modality for treating PCV. However, the costeffectiveness of combination therapy should be carefully assessed, and a strategy to select the appropriate candidates for this therapy should be established because of its expense.

In the future, it will be important to evaluate the longterm results of each modality with a large number of subjects to determine the efficacy and durability of this therapy, particularly in PCV patients.

\section{Conclusions}

As described above, PCV is a unique phenotype of AMD which should be handled with a different strategy from tAMD. In particular, the effects of various treatment modalities may be different between tAMD and PCV, which necessitate further investigation to determine the correct indications for PDT, anti-VEGF therapy and combination therapy for PCV. Moreover, genetic association analyses may disclose the difference in the pathogenesis between tAMD and PCV, and may indicate how to choose the appropriate interventions for each PCV patient.

\section{Disclosure Statement}

The authors report no conflicts of interest. 


\section{References}

1 Yannuzzi LA, Sorenson J, Spaide RF, et al: Idiopathic polypoidal choroidal vasculopathy (IPCV). Retina 1990;10:1-8.

-2 Kleiner RC, Brucker AJ, Johnston RL: The posterior uveal bleeding syndrome. Retina 1990;10:9-17.

- 3 Stern RM, Zakov ZN, Zegarra H, Gutman FA: Multiple recurrent serosanguineous retinal pigment epithelial detachments in black women. Am J Ophthalmol 1985;100:560569.

4 Yannuzzi LA, Ciardella A, Spaide RF, et al: The expanding clinical spectrum of idiopathic polypoidal choroidal vasculopathy. Arch Ophthalmol 1997;115:478-485.

-5 Yannuzzi LA, Wong DW, Sforzolini BS, Goldbaum M, Tang KC, Spaide RF, Freund KB, Slakter JS, Guyer DR, Sorenson JA, Fisher Y, Maberley D, Orlock DA: Polypoidal choroidal vasculopathy and neovascularized agerelated macular degeneration. Arch Ophthalmol 1999;117:1503-1510.

6 Lim TH, Laude A, Tan CS: Polypoidal choroidal vasculopathy: an angiographic discussion. Eye (Lond) 2010;24:483-490.

7 Goldman DR, Freund KB, McCannel CA, Sarraf D: Peripheral polypoidal choroidal vasculopathy as a cause of peripheral exudative hemorrhagic chorioretinopathy: a report of 10 eyes. Retina 2013;33:48-55.

-8 Mantel I, Schalenbourg A, Zografos L: Peripheral exudative hemorrhagic chorioretinopathy: polypoidal choroidal vasculopathy and hemodynamic modifications. Am J Ophthalmol 2012;153:910-922.

$\checkmark 9$ Laude A, Cackett PD, Vithana EN, Yeo IY, Wong D, Koh AH, Wong TY, Aung T: Polypoidal choroidal vasculopathy and neovascular age-related macular degeneration: same or different disease? Prog Retin Eye Res 2010;29: 19-29.

10 Uyama M, Matsubara T, Fukushima I, et al: Idiopathic polypoidal choroidal vasculopathy in Japanese patients. Arch Ophthalmol 1999; 117:1035-1042.

11 Sho K, Takahashi K, Yamada H, et al: Polypoidal choroidal vasculopathy: incidence, demographic features, and clinical characteristics. Arch Ophthalmol 2003;121:1392-1396.

-12 Uyama M, Wada M, Nagai Y, et al: Polypoidal choroidal vasculopathy: natural history. Am J Ophthalmol 2002;133:639-648.

13 Bessho H, Honda S, Imai H, Negi A: Natural course and funduscopic findings of polypoidal choroidal vasculopathy in a Japanese population over one year of follow-up. Retina 2011;31:1598-1602.

14 Honda S, Kurimoto Y, Kagotani Y, et al: Photodynamic therapy for typical age-related macular degeneration and polypoidal choroidal vasculopathy: a 30-month multicenter study in Hyogo, Japan. Jpn J Ophthalmol 2009;53:593-597.

15 Honda S, Imai H, Yamashiro K, et al: Comparative assessment of photodynamic therapy for typical age-related macular degeneration and polypoidal choroidal vasculopathy: a multicenter study in Hyogo prefecture, Japan. Ophthalmologica 2009;223:333-338.

16 Matsumiya W, Honda S, Kusuhara S, Tsukahara Y, Negi A: Effectiveness of intravitreal ranibizumab in exudative age-related macular degeneration (AMD): comparison between typical neovascular AMD and polypoidal choroidal vasculopathy over a 1 year follow-up. BMC Ophthalmol 2013;13:10.

17 Matsumiya W, Honda S, Bessho H, Kusuhara S, Tsukahara Y, Negi A: Early responses to intravitreal ranibizumab in typical neovascular age-related macular degeneration and polypoidal choroidal vasculopathy. J Ophthalmol 2011;2011:742020.

18 Kondo N, Honda S, Ishibashi K, Tsukahara Y, Negi A: LOC387715/HTRA1 variants in polypoidal choroidal vasculopathy and age-related macular degeneration in a Japanese population. Am J Ophthalmol 2007;144:608-612.

19 Gotoh N, Nakanishi H, Hayashi H, Yamada R, Otani A, Tsujikawa A, Yamashiro K, Tamura H, Saito M, Saito K, Iida T, Matsuda F, Yoshimura N: ARMS2 (LOC387715) variants in Japanese patients with exudative agerelated macular degeneration and polypoidal choroidal vasculopathy. Am J Ophthalmol 2009;147:1037-1041.

20 Hayashi H, Yamashiro K, Gotoh N, Nakanishi H, Nakata I, Tsujikawa A, Otani A, Saito M, Iida T, Matsuo K, Tajima K, Yamada R, Yoshimura $\mathrm{N}$ : $\mathrm{CFH}$ and ARMS2 variations in age-related macular degeneration, polypoidal choroidal vasculopathy, and retinal angiomatous proliferation. Invest Ophthalmol Vis Sci 2010;51:5914-5919.

21 Fuse N, Mengkegale M, Miyazawa A, Abe T, Nakazawa T, Wakusawa R, Nishida K: Polymorphisms in ARMS2 (LOC387715) and LOXL1 genes in the Japanese with age-related macular degeneration. Am J Ophthalmol 2011;151:550-556.

-22 Tanaka K, Nakayama T, Yuzawa M, Wang Z, Kawamura A, Mori R, Nakashizuka H, Sato N, Mizutani Y: Analysis of candidate genes for age-related macular degeneration subtypes in the Japanese population. Mol Vis 2011;17:2751-2758.

23 Yanagisawa S, Kondo N, Miki A, Matsumiya W, Kusuhara S, Tsukahara Y, Honda S, Negi A: Difference between age-related macular degeneration and polypoidal choroidal vasculopathy in the hereditary contribution of the A69S variant of the age-related maculopathy susceptibility 2 gene (ARMS2). Mol Vis 2011;17:3574-3582.

24 Liang XY, Lai TY, Liu DT, Fan AH, Chen LJ, Tam PO, Chiang SW, Ng TK, Lam DS, Pang CP: Differentiation of exudative age-related macular degeneration and polypoidal choroidal vasculopathy in the ARMS2/HTRA1 locus. Invest Ophthalmol Vis Sci 2012;53:31753182.
25 Zhang X, Li M, Wen F, Zuo C, Chen H, Wu K, Zeng R: Different impact of high-density lipoprotein-related genetic variants on polypoidal choroidal vasculopathy and neovascular age-related macular degeneration in a Chinese Han population. Exp Eye Res 2013;108: $16-22$.

-26 Tsujikawa A, Ojima Y, Yamashiro K, Nakata I, Ooto S, Tamura H, Nakanishi H, Hayashi H, Otani A, Yoshimura N: Association of lesion size and visual prognosis to polypoidal choroidal vasculopathy. Am J Ophthalmol 2011;151:961-972.

27 Miki A, Honda S, Kondo N, Negi A: The association of age-related maculopathy susceptibility 2 (ARMS2) and complement factor $\mathrm{H}$ $(\mathrm{CFH})$ variants with two angiographic subtypes of polypoidal choroidal vasculopathy. Ophthalmic Genet 2013;34:146-150.

28 Imamura Y, Engelbert M, Iida T, Freund KB, Yannuzzi LA: Polypoidal choroidal vasculopathy: a review. Surv Ophthalmol 2010;55: 501-515.

29 Al-Rashaed S: Idiopathic polypoidal choroidal vasculopathy in a young man: case report and literature review. Middle East Afr J Ophthalmol 2008;15:90-93.

30 Maruko I, Iida T, Saito M, Nagayama D, Saito $\mathrm{K}$ : Clinical characteristics of exudative agerelated macular degeneration in Japanese patients. Am J Ophthalmol 2007;144:15-22.

31 Chang YC, Wu WC: Polypoidal choroidal vasculopathy in Taiwanese patients. Ophthalmic Surg Lasers Imaging 2009;40:576-81.

32 Wen F, Chen C, Wu D, Li H: Polypoidal choroidal vasculopathy in elderly Chinese patients. Graefes Arch Clin Exp Ophthalmol 2004;242:625-629.

33 Liu Y, Wen F, Huang S, Luo G, Yan H, Sun Z, Wu D: Subtype lesions of neovascular age-related macular degeneration in Chinese patients. Graefes Arch Clin Exp Ophthalmol 2007;245:1441-1445.

- 34 Song SJ, Youm DJ, Chang Y, Yu HG: Agerelated macular degeneration in a screened South Korean population: prevalence, risk factors, and subtypes. Ophthalmic Epidemiol 2009; 16:304-310.

35 Byeon SH, Lee SC, Oh HS, Kim SS, Koh HJ, Kwon OW: Incidence and clinical patterns of polypoidal choroidal vasculopathy in Korean patients. Jpn J Ophthalmol 2008;52:57-62.

36 Ciardella AP, Donsoff IM, Huang SJ, Costa DL, Yannuzzi LA: Polypoidal choroidal vasculopathy. Surv Ophthalmol 2004;49:25-37.

37 Tsujikawa A, Nakanishi H, Ojima Y, Iwama D, Tamura H, Otani A, Yoshimura N: Macular polypoidal choroidal vasculopathy with a remote lesion. Clin Experiment Ophthalmol 2008;36:817-823.

38 Ueta T, Obata R, Inoue Y, et al: Background comparison of typical age-related macular degeneration and polypoidal choroidal vasculopathy in Japanese patients. Ophthalmology 2009;116:2400-2406. 
-39 Sakurada Y, Yoneyama S, Imasawa M, Iijima $\mathrm{H}$ : Systemic risk factors associated with polypoidal choroidal vasculopathy and neovascular age-related macular degeneration. Retina 2013;33:841-845.

40 Hirami Y, Tsujikawa A, Otani A, Yodoi Y, Aikawa $\mathrm{H}$, Mandai $\mathrm{M}$, Yoshimura N: Hemorrhagic complications after photodynamic therapy for polypoidal choroidal vasculopathy. Retina 2007;27:335-341.

41 Kikuchi M, Nakamura M, Ishikawa K, et al: Elevated C-reactive protein levels in patients with polypoidal choroidal vasculopathy and patients with neovascular age-related macular degeneration. Ophthalmology 2007;114: 1722-1727.

42 Cackett P, Yeo I, Cheung CM, Vithana EN, Wong D, Tay WT, Tai ES, Aung T, Wong TY: Relationship of smoking and cardiovascular risk factors with polypoidal choroidal vasculopathy and age-related macular degeneration in Chinese persons. Ophthalmology 2011;118:846-852.

-43 Japanese Study Group of Polypoidal Choroidal Vasculopathy: Criteria for diagnosis of polypoidal choroidal vasculopathy (in Japanese). Nippon Ganka Gakkai Zasshi 2005; 109:417-427.

44 Otsuji T, Tsumura A, Takahashi K, et al: Evaluation of cases of polypoidal choroidal vasculopathy showing classic choroidal neovascularisation in their natural course. J Jpn Ophthalmol Soc 2006;110:454-461.

45 Tamura H, Tsujikawa A, Otani A, et al: Polypoidal choroidal vasculopathy appearing as classic choroidal neovascularisation on fluorescein angiography. Br J Ophthalmol 2007; 91:1152-1159, erratum in $\mathrm{Br} \mathrm{J}$ Ophthalmol 2007;91:1572.

46 Musashi K, Tsujikawa A, Hirami Y, Otani A, Yodoi Y, Tamura H, Yoshimura N: Microrips of the retinal pigment epithelium in polypoidal choroidal vasculopathy. Am J Ophthalmol 2007; 143:883-885.

-47 Tsujikawa A, Hirami Y, Nakanishi H, Ojima Y, Aikawa H, Tamura H, Otani A, Yoshimura $\mathrm{N}$ : Retinal pigment epithelial tear in polypoidal choroidal vasculopathy. Retina 2007;27: 832-838.

48 Cackett P, Wong D, Yeo I: A classification system for polypoidal choroidal vasculopathy. Retina 2009;29:187-191.

49 Hirami Y, Mandai M, Takahashi M, Teramukai S, Tada H, Yoshimura N: Association of clinical characteristics with disease subtypes, initial visual acuity, and visual prognosis in neovascular age-related macular degeneration. Jpn J Ophthalmol 2009;53:396-407.

50 Yuzawa M, Mori R, Kawamura A: The origins 63 of polypoidal choroidal vasculopathy. $\mathrm{Br} \mathrm{J}$ Ophthalmol 2005;89:602-607.

51 Okubo A, Ito M, Sameshima M, Uemura A, Sakamoto T: Pulsatile blood flow in the polypoidal choroidal vasculopathy. Ophthalmology 2005;112:1436-1441.
Byeon SH, Lew YJ, Lee SC, Kwon OW: Clinical features and follow-up results of pulsating polypoidal choroidal vasculopathy treated with photodynamic therapy. Acta Ophthalmol 2010;88:660-668.

53 Sasahara M, Tsujikawa A, Musashi K, Gotoh N, Otani A, Mandai M, Yoshimura N: Polypoidal choroidal vasculopathy with choroidal vascular hyperpermeability. Am J Ophthalmol 2006;142:601-607.

54 Koizumi H, Yamagishi T, Yamazaki T, Kinoshita S: Relationship between clinical characteristics of polypoidal choroidal vasculopathy and choroidal vascular hyperpermeability. Am J Ophthalmol 2013;155:305313.

55 Okubo A, Sameshima M, Uemura A, Kanda $\mathrm{S}$, Ohba N: Clinicopathological correlation of polypoidal choroidal vasculopathy revealed by ultrastructural study. $\mathrm{Br} \mathrm{J}$ Ophthalmol 2002;86:1093-1098.

56 Okubo A, Hirakawa M, Ito M, Sameshima M, Sakamoto T: Clinical features of early and late stage polypoidal choroidal vasculopathy characterized by lesion size and disease duration. Graefes Arch Clin Exp Ophthalmol 2008;246:491-499.

57 Kawamura A, Yuzawa M, Mori R, Haruyama $\mathrm{M}$, Tanaka K: Indocyanine green angiographic and optical coherence tomographic findings support classification of polypoidal choroidal vasculopathy into two types. Acta Ophthalmol 2013;91:e474-e481.

58 Tanaka K, Nakayama T, Mori R, Sato N, Kawamura A, Mizutani Y, Yuzawa M: Associations of complement factor $\mathrm{H}(\mathrm{CFH})$ and age-related maculopathy susceptibility 2 (ARMS2) genotypes with subtypes of polypoidal choroidal vasculopathy. Invest Ophthalmol Vis Sci 2011;52:7441-7444.

59 Miki A, Honda S, Kondo N, Negi A: The association of age-related maculopathy susceptibility 2 (ARMS2) and complement factor $\mathrm{H}$ $(\mathrm{CFH})$ variants with two angiographic subtypes of polypoidal choroidal vasculopathy. Ophthalmic Genet 2013;34:146-150.

60 Yuzawa M: Polypoidal choroidal vasculopathy (in Japanese). Nihon Ganka Gakkai Zasshi 2012;116:200-231, discussion 232.

61 Tsujikawa A: Usefulness of optical coherence tomography for differential diagnosis: polypoidal lesions and type 2 choroidal neovascularization (in Japanese). Jpn J Clin Ophthalmol (Rinsho Ganka) 2013;67:1058-1063.

62 Yang LH, Jonas JB, Wei WB: Optical coherence tomographic enhanced depth imaging of polypoidal choroidal vasculopathy. Retina 2013;33:1584-1589.

63 Nagase S, Miura M, Makita S, Iwasaki T, Goto $\mathrm{H}$, Yasuno Y: High-penetration optical coherence tomography with enhanced depth imaging of polypoidal choroidal vasculopathy. Ophthalmic Surg Lasers Imaging 2012;43:e5e39.
64 Kim SW, Oh J, Kwon SS, Yoo J, Huh K: Comparison of choroidal thickness among patients with healthy eyes, early age-related maculopathy, neovascular age-related macular degeneration, central serous chorioretinopathy, and polypoidal choroidal vasculopathy. Retina 2011;31:1904-1911.

-65 Koizumi H, Yamagishi T, Yamazaki T, Kawasaki R, Kinoshita S: Subfoveal choroidal thickness in typical age-related macular degeneration and polypoidal choroidal vasculopathy. Graefes Arch Clin Exp Ophthalmol 2011;249: 1123-1128.

66 Chung SE, Kang SW, Lee JH, Kim YT: Choroidal thickness in polypoidal choroidal vasculopathy and exudative age-related macular degeneration. Ophthalmology 2011;118:840-845.

67 Rishi P, Rishi E, Mathur G, Raval V: Ocular perfusion pressure and choroidal thickness in eyes with polypoidal choroidal vasculopathy, wet-age-related macular degeneration, and normals. Eye (Lond) 2013;27:1038-1043.

68 Chung SE, Kang SW, Kim JH, Kim YT, Park Y: Engorgement of vortex vein and polypoidal choroidal vasculopathy. Retina 2013;33:834840 .

-69 Yamagishi T, Koizumi H, Yamazaki T, Kinoshita S: Fundus autofluorescence in polypoidal choroidal vasculopathy. Ophthalmology 2012;119:1650-1657.

70 Suzuki M, Gomi F, Sawa M, Ueno C, Nishida $\mathrm{K}$ : Changes in fundus autofluorescence in polypoidal choroidal vasculopathy during 3 years of follow-up. Graefes Arch Clin Exp Ophthalmol 2013;251:2331-2337.

-71 Terasaki H, Miyake Y, Suzuki T, Nakamura M, Nagasaka T: Polypoidal choroidal vasculopathy treated with macular translocation: clinical pathological correlation. Br J Ophthalmol 2002;86:321-327.

72 Kuroiwa S, Tateiwa H, Hisatomi T, Ishibashi T, Yoshimura N: Pathological features of surgically excised polypoidal choroidal vasculopathy membranes. Clin Exp Ophthalmol 2004; 32:297-302.

-73 Nakajima M, Yuzawa M, Shimada H, Mori R: Correlation between indocyanine green angiographic findings and histopathology of polypoidal choroidal vasculopathy. Jpn J Ophthalmol 2004;48:249-255.

74 Nakashizuka H, Mitsumata M, Okisaka S, Shimada H, Kawamura A, Mori R, Yuzawa M: Clinicopathologic findings in polypoidal choroidal vasculopathy. Invest Ophthalmol Vis Sci 2008;49:4729-4737.

75 Klein RJ, Zeiss C, Chew EY, et al: Complement factor $\mathrm{H}$ polymorphism in age-related macular degeneration. Science 2005;308:385389.

76 Edwards AO, Ritter R III, Abel KJ, et al: Complement factor $\mathrm{H}$ polymorphism and age-related macular degeneration. Science 2005; 308:421-424

77 Haines JL, Hauser MA, Schmidt S, et al: Complement factor $\mathrm{H}$ variant increases the risk of age-related macular degeneration. Science 2005;308:419-421. 
78 Maller J, George S, Purcell S, et al: Common variation in three genes, including a noncoding variant in $\mathrm{CFH}$, strongly influences risk of age-related macular degeneration. Nat Genet 2006;38:1055-1059.

-79 Li M, Atmaca-Sonmez P, Othman M, et al: $\mathrm{CFH}$ haplotypes without the $\mathrm{Y} 402 \mathrm{H}$ coding variant show strong association with susceptibility to age-related macular degeneration. Nat Genet 2006;38:1049-1054.

80 Dewan A, Liu M, Hartman S, et al: HTRA1 promoter polymorphism in wet age-related macular degeneration. Science 2006;314:989992.

81 Yang Z, Camp NJ, Sun H, et al: A variant of the HTRA1 gene increases susceptibility to age-related macular degeneration. Science 2006;314:992-993.

82 Fritsche LG, Loenhardt T, Janssen A, et al: Age-related macular degeneration is associated with an unstable ARMS2 (LOC387715) mRNA. Nat Genet 2008;40:892-896.

83 Kanda A, Chen W, Othman M, et al: A variant of mitochondrial protein LOC387715/ ARMS2, not HTRA1, is strongly associated with age-related macular degeneration. Proc Natl Acad Sci USA 2007;104:16227-16232.

84 Ormsby RJ, Ranganathan S, Tong JC, et al: Functional and structural implications of the complement factor $\mathrm{H} \mathrm{Y} 402 \mathrm{H}$ polymorphism associated with age-related macular degeneration. Invest Ophthalmol Vis Sci 2008;49: 1763-1770.

85 The International HapMap Consortium: The International HapMap Project. Nature 2003; 426:789-796.

86 Okamoto H, Umeda S, Obazawa M, et al: Complement factor $\mathrm{H}$ polymorphisms in Japanese population with age-related macular degeneration. Mol Vis 2006;12:156-158.

87 Gotoh N, Yamada R, Hiratani H, et al: No association between complement factor $\mathrm{H}$ gene polymorphism and exudative age-related macular degeneration in Japanese. Hum Genet 2006;120:139-143.

88 Fuse N, Miyazawa A, Mengkegale M, et al: Polymorphisms in complement factor $\mathrm{H}$ and hemicentin-1 genes in a Japanese population with dry-type age-related macular degeneration. Am J Ophthalmol 2006;142:1074-1076.

89 Mori K, Gehlbach PL, Kabasawa S, et al: Coding and noncoding variants in the $\mathrm{CFH}$ gene and cigarette smoking influence the risk of age-related macular degeneration in a Japanese population. Invest Ophthalmol Vis Sci 2007;48:5315-5319.

90 Kondo N, Bessho H, Honda S, Negi A: Complement factor $\mathrm{H} \mathrm{Y} 402 \mathrm{H}$ variant and risk of age-related macular degeneration in Asians: a systematic review and meta-analysis. Ophthalmology 2011;118:339-344.

\$1 Yuan D, Yang Q, Liu X, Yuan D, Yuan S, Xie P, Liu Q: Complement factor H Val62Ile variant and risk of age-related macular degeneration: a meta-analysis. Mol Vis 2013;19:374383.
92 Ng TK, Chen LJ, Liu DT, et al: Multiple gene polymorphisms in the complement factor $\mathrm{H}$ gene are associated with exudative age-related macular degeneration in Chinese. Invest Ophthalmol Vis Sci 2008;49:3312-3317.

$\$ 93$ Kim NR, Kang JH, Kwon OW, et al: Association between complement factor $\mathrm{H}$ gene polymorphisms and neovascular age-related macular degeneration in Koreans. Invest Ophthalmol Vis Sci 2008;49:2071-2076.

94 Chen H, Liu K, Chen LJ, Hou P, Chen W, Pang CP: Genetic associations in polypoidal choroidal vasculopathy: a systematic review and meta-analysis. Mol Vis 2012;18:816829.

95 Yuan D, Yuan D, Yuan S, Liu Q: The agerelated maculopathy susceptibility 2 polymorphism and polypoidal choroidal vasculopathy in Asian populations: a meta-analysis. Ophthalmology 2013;120:2051-2057.

96 Cheng Y, Huang L, Li X, Zhou P, Zeng W, Zhang C: Genetic and functional dissection of ARMS2 in age-related macular degeneration and polypoidal choroidal vasculopathy. PLoS One 2013;8:e53665.

$\$ 97$ Jiang JJ, Wu X, Zhou P, Yu WZ, Huang LZ, Li XX: Meta-analysis of the relationship between the LOC387715/ARMS2 polymorphism and polypoidal choroidal vasculopathy. Genet Mol Res 2012;11:4256-4267.

-98 Lima LH, Schubert C, Ferrara DC, Merriam JE, Imamura Y, Freund KB, Spaide RF, Yannuzzi LA, Allikmets R: Three major loci involved in age-related macular degeneration are also associated with polypoidal choroidal vasculopathy. Ophthalmology 2010;117: 1567-1570.

99 Kondo N, Honda S, Kuno S, Negi A: Coding variant $\mathrm{I} 62 \mathrm{~V}$ in the complement factor $\mathrm{H}$ gene is strongly associated with polypoidal choroidal vasculopathy. Ophthalmology 2009;116:304-310.

100 Jones A, Kumar S, Zhang N, Tong Z, Yang JH, Watt C, Anderson J, Amrita, Fillerup H, McCloskey M, Luo L, Yang Z, Ambati B, Marc R, Oka C, Zhang K, Fu Y: Increased expression of multifunctional serine protease, HTRA1, in retinal pigment epithelium induces polypoidal choroidal vasculopathy in mice. Proc Natl Acad Sci USA 2011;108: 14578-14583.

101 Vierkotten S, Muether PS, Fauser S: Overexpression of HTRA1 leads to ultrastructural changes in the elastic layer of Bruch's membrane via cleavage of extracellular matrix components. PLoS One 2011;6:e22959.

102 Lee KY, Vithana EN, Mathur R, et al: Association analysis of $\mathrm{CFH}, \mathrm{C} 2, \mathrm{BF}$, and HTRA1 gene polymorphisms in Chinese patients with polypoidal choroidal vasculopathy. Invest Ophthalmol Vis Sci 2008;49:26132619.

103 Kondo N, Honda S, Ishibashi K, et al: Elastin gene polymorphisms in neovascular age-related macular degeneration and polypoidal choroidal vasculopathy. Invest Ophthalmol Vis Sci 2008;49:1101-1105.
04 Yamashiro K, Mori K, Nakata I, Tsuchihashi T, Horie-Inoue K, Nakanishi H, Tsujikawa A, Saito M, Iida T, Yamada R, Matsuda F, Inoue $\mathrm{S}$, Awata $\mathrm{T}$, Yoneya S, Yoshimura $\mathrm{N}$ : Association of elastin gene polymorphism to age-related macular degeneration and polypoidal choroidal vasculopathy. Invest Ophthalmol Vis Sci 2011;52:8780-8784.

105 Zhang X, Wen F, Zuo C, Li M, Chen H, Wu $\mathrm{K}$ : Association of genetic variation on chromosome 9p21 with polypoidal choroidal vasculopathy and neovascular age-related macular degeneration. Invest Ophthalmol Vis Sci 2011;52:8063-8067.

106 Tsujikawa A, Sasahara M, Otani A, et al: Pigment epithelial detachment in polypoidal choroidal vasculopathy. Am J Ophthalmol 2007; 143:102-111.

107 Ciardella AP, Donsoff IM, Huang SJ, et al: Polypoidal choroidal vasculopathy. Surv Ophthalmol 2004;49:25-37.

108 Kikuchi M, Nakamura M, Ishikawa K, et al: Elevated C-reactive protein levels in patients with polypoidal choroidal vasculopathy and patients with neovascular age-related macular degeneration. Ophthalmology 2007;114: 1722-1727.

109 Sakurada Y, Kubota T, Imasawa M, Tsumura T, Mabuchi F, Tanabe N, Iijima H: Angiographic lesion size associated with LOC387715 A69S genotype in subfoveal polypoidal choroidal vasculopathy. Retina 2009;29:1522-1526.

110 Bessho H, Honda S, Kondo N, Negi A: The association of ARMS2 polymorphisms with phenotype in typical neovascular age-related macular degeneration and polypoidal choroidal vasculopathy. Mol Vis 2011;17: 977-982.

111 Sakurada Y, Kubota T, Mabuchi F, et al: Association of LOC387715 A69S with vitreous hemorrhage in polypoidal choroidal vasculopathy. Am J Ophthalmol 2008;145:10581062.

112 Gomi F, Ohji M, Sayanagi K, Sawa M, Sakaguchi $\mathrm{H}$, Oshima $\mathrm{Y}$, et al: One-year outcomes of photodynamic therapy in age-related macular degeneration and polypoidal choroidal vasculopathy in Japanese patients. Ophthalmology 2008;115:141-146.

113 Chan WM, Lam DS, Lai TY, Liu DT, Li KK, Yao Y, et al: Photodynamic therapy with verteporfin for symptomatic polypoidal choroidal vasculopathy. Ophthalmology 2004;111:1576-1584.

114 Akaza E, Yuzawa M, Matsumoto Y, Kashiwakura S, Fujita K, Mori R: Role of photodynamic therapy in polypoidal choroidal vasculopathy. Jpn J Ophthalmol 2007;51:270277.

115 Lee WK, Kim KS, Kim W, Lee SB, Jeon S Responses to photodynamic therapy in patients with polypoidal choroidal vasculopathy consisting of polyps resembling grape clusters. Am J Ophthalmol 2012;154:355365 . 
-116 Lee WK, Lee PY, Lee SK: Photodynamic therapy for polypoidal choroidal vasculopathy: vaso-occlusive effect on the branching vascular network and origin of recurrence. Jpn J Ophthalmol 2008;52:108-115.

-117 Koh A, Lee WK, Chen LJ, Chen SJ, Hashad Y, Kim H, Lai TY, Pilz S, Ruamviboonsuk P, Tokaji E, Weisberger A, Lim TH: EVEREST Study: efficacy and safety of verteporfin photodynamic therapy in combination with ranibizumab or alone versus ranibizumab monotherapy in patients with symptomatic macular polypoidal choroidal vasculopathy. Retina 2012;32:1453-1464.

118 Mori R, Yuzawa M, Lee Z, Haruyama M, Akaza E: Factors influencing visual outcome of polypoidal choroidal vasculopathy one year after photodynamic therapy. Graefes Arch Clin Exp Ophthalmol 2010;248:12331239.

-119 Hikichi T, Ohtsuka H, Higuchi M, Matsushita T, Ariga H, Kosaka S, Matsushita R, Takami K: Factors predictive of visual acuity outcomes 1 year after photodynamic therapy in Japanese patients with polypoidal choroidal vasculopathy. Retina 2011;31:857865.

120 Kurashige Y, Otani A, Sasahara M, Yodoi Y, Tamura H, Tsujikawa A, et al: Two-year results of photodynamic therapy for polypoidal choroidal vasculopathy. Am J Ophthalmol 2008;146:513-519.

121 Akaza E, Yuzawa M, Mori R: Three-year follow-up results of photodynamic therapy for polypoidal choroidal vasculopathy. Jpn J Ophthalmol 2011;55:39-44.

122 Leal S, Silva R, Figueira J, Cachulo ML, Pires I, de Abreu JR, Cunha-Vaz JG: Photodynamic therapy with verteporfin in polypoidal choroidal vasculopathy: results after 3 years of follow-up. Retina 2010;30:11971205.

123 Miki A, Honda S, Kojima H, Nishizaki M, Nagai T, Fujihara M, Uenishi M, Kita M, Kurimoto Y, Negi A, Hyogo Macular Disease Study Group: Visual outcome of photodynamic therapy for typical neovascular age-related macular degeneration and polypoidal choroidal vasculopathy over 5 years of follow-up. Jpn J Ophthalmol 2013;57: 301-307.

124 Tsuchihashi T, Mori K, Ueyama K, Yoneya S: Five-year results of photodynamic therapy with verteporfin for Japanese patients with neovascular age-related macular degeneration. Clin Ophthalmol 2013;7:615620.

125 Kang HM, Kim YM, Koh HJ: Five-year follow-up results of photodynamic therapy for polypoidal choroidal vasculopathy. Am J Ophthalmol 2013;155:438-447.

126 Oishi A, Mandai M, Kimakura M, Nishida A, Kurimoto Y: Characteristics of fine vascular network pattern associated with recurrence of polypoidal choroidal vasculopathy. Eye (Lond) 2011;25:1020-1026.
127 Feng X, Xiao J, Longville B, Tan AX, Wu XN, et al: Complement factor $\mathrm{H} \mathrm{Y} 402 \mathrm{H}$ and Creactive protein polymorphism and photodynamic therapy response in age-related macular degeneration. Ophthalmology 2009;116:1908-1912.

128 Chowers I, Cohen Y, Goldenberg-Cohen N, Vicuna-Kojchen J, Lichtinger A, et al: Association of complement factor $\mathrm{H} \mathrm{Y} 402 \mathrm{H}$ polymorphism with phenotype of neovascular age related macular degeneration in Israel. Mol Vis 2008;14:1829-1834.

-129 Brantley MA Jr, Edelstein SL, King JM, Plotzke MR, Apte RS, et al: Association of complement factor $\mathrm{H}$ and LOC387715 genotypes with response of exudative age-related macular degeneration to photodynamic therapy. Eye (Lond) 2009;23:626-631.

130 Seitsonen SP, Jarvela IE, Meri S, Tommila PV, Ranta PH, et al: The effect of complement factor $\mathrm{H} Y 402 \mathrm{H}$ polymorphism on the outcome of photodynamic therapy in agerelated macular degeneration. Eur J Ophthalmol 2007;17:943-949.

131 Goverdhan SV, Hannan S, Newsom RB, Luff AJ, Griffiths $\mathrm{H}$, et al: An analysis of the $\mathrm{CFH}$ $\mathrm{Y} 402 \mathrm{H}$ genotype in AMD patients and controls from the UK, and response to PDT treatment. Eye (Lond) 2008;22:849-854.

132 Bessho H, Honda S, Kondo N, et al: Positive association of complement factor $\mathrm{H}$ gene variants with the effect of photodynamic therapy in polypoidal choroidal vasculopathy. J Clin Exp Ophthalmol 2011;2:122.

133 Sakurada Y, Kubota T, Imasawa M, Mabuchi F, Tanabe N, Iijima $\mathrm{H}$ : Association of LOC387715 A69S genotype with visual prognosis after photodynamic therapy for polypoidal choroidal vasculopathy. Retina 2010;30:1616-1621.

134 Nakata I, Yamashiro K, Yamada R, Gotoh N, Nakanishi H, Hayashi H, Tsujikawa A, Otani A, Ooto S, Tamura H, Saito M, Saito K, Iida T, Oishi A, Kurimoto Y, Matsuda F, Yoshimura N: Genetic variants in pigment epithelium-derived factor influence response of polypoidal choroidal vasculopathy to photodynamic therapy. Ophthalmology 2011;118:1408-1415.

-135 Honda S, Bessho H, Kondo N, Kusuhara S, Tsukahara Y, Negi A: Positive association of CD36 gene variants with the visual outcome of photodynamic therapy in polypoidal choroidal vasculopathy. Mol Vis 2012;18:27962804.

136 Schmidt-Erfurth UM, Richard G, Augustin A, Aylward WG, Bandello F, Corcòstegui B, Cunha-Vaz J, Gaudric A, Leys A, Schlingemann RO, European Society for Retina Specialists' Guidelines Committee (EURETINA): Guidance for the treatment of neovascular age-related macular degeneration. Acta Ophthalmol Scand 2007;85: 486-494.
137 Ip MS, Scott IU, Brown GC, Brown MM, Ho AC, Huang SS, Recchia FM: Anti-vascular endothelial growth factor pharmacotherapy for age-related macular degeneration: a report by the American Academy of Ophthalmology. Ophthalmology 2008;115:18371846.

138 Tsujikawa A, Ooto S, Yamashiro K, Tamura H, Otani A, Yoshimura N: Treatment of polypoidal choroidal vasculopathy by intravitreal injection of bevacizumab. Jpn J Ophthalmol 2010;54:310-319.

139 Gomi F, Sawa M, Sakaguchi H, Tsujikawa M, Oshima Y, Kamei M, Tano Y: Efficacy of intravitreal bevacizumab for polypoidal choroidal vasculopathy. Br J Ophthalmol 2008;92:70-73.

140 Stangos AN, Gandhi JS, Nair-Sahni J, Heimann H, Pournaras CJ, Harding SP: Polypoidal choroidal vasculopathy masquerading as neovascular age-related macular degeneration refractory to ranibizumab. Am J Ophthalmol 2010;150:666-673.

141 Song MH, Ryu HW, Roh YJ: One-year results of intravitreal ranibizumab with or without photodynamic therapy for polypoidal choroidal vasculopathy. Ophthalmologica 2011;226:119-126.

142 Reche-Frutos J, Calvo-Gonzalez C, DonateLopez J, Garcia-Feijoo J, Leila M, GarciaSanchez J: Short-term anatomic effect of ranibizumab for polypoidal choroidal vasculopathy. Eur J Ophthalmol 2008; 18: 645-648.

143 Hikichi T, Ohtsuka H, Higuchi M, Matsushita T, Ariga H, Kosaka S, Matsushita R, Takami K: Improvement of angiographic findings of polypoidal choroidal vasculopathy after intravitreal injection of ranibizumab monthly for 3 months. Am J Ophthalmol 2010;150:674-682.

144 Koh AH, Expert PCV Panel, Chen LJ, Chen SJ, Chen Y, Giridhar A, Iida T, Kim H, Yuk Yau Lai T, Lee WK, Li X, Han Lim T, Ruamviboonsuk P, Sharma T, Tang S, Yuzawa M: Polypoidal choroidal vasculopathy: evidence-based guidelines for clinical diagnosis and treatment. Retina 2013;33:686-716.

145 Oishi A, Kojima H, Mandai M, Honda S, Matsuoka T, Oh H, Kita M, Nagai T, Fujihara M, Bessho N, Uenishi M, Kurimoto Y, Negi A: Comparison of the effect of ranibizumab and verteporfin for polypoidal choroidal vasculopathy: 12-month LAPTOP study results. Am J Ophthalmol 2013;156: 644-651.

146 Koizumi H, Yamagishi T, Yamazaki T, Kinoshita S: Predictive factors of resolved retinal fluid after intravitreal ranibizumab for polypoidal choroidal vasculopathy. Br J Ophthalmol 2011;95:1555-1559.

$\checkmark 147$ Yamashiro K, Tomita K, Tsujikawa A, et al: Factors associated with the response of agerelated macular degeneration to intravitreal ranibizumab treatment. Am J Ophthalmol 2012;154:125-136. 
148 Chen H, Yu KD, Xu GZ: Association between variant $\mathrm{Y} 402 \mathrm{H}$ in age-related macular degeneration (AMD) susceptibility gene $\mathrm{CFH}$ and treatment response of AMD: a meta-analysis. PLoS One 2012;7:e42464.

149 Francis PJ: The influence of genetics on response to treatment with ranibizumab $(\mathrm{Lu}-$ centis) for age-related macular degeneration: the Lucentis Genotype Study (an American Ophthalmological Society thesis). Trans Am Ophthalmol Soc 2011;109:115156.

150 Orlin A, Hadley D, Chang W, et al: Association between high-risk disease loci and response to anti-vascular endothelial growth factor treatment for wet age-related macular degeneration. Retina 2012;32:4-9.

151 Kloeckener-Gruissem B, Barthelmes D, Labs $S$, et al: Genetic association with response to intravitreal ranibizumab in patients with neovascular AMD. Invest Ophthalmol Vis Sci 2011;52:4694-4702.
152 McKibbin M, Ali M, Bansal S, et al: CFH, VEGF and HTRA1 promoter genotype may influence the response to intravitreal ranibizumab therapy for neovascular age-related macular degeneration. Br J Ophthalmol 2012;96:208-212.

153 Lee AY, Raya AK, Kymes SM, Shiels A, Brantley MA Jr: Pharmacogenetics of complement factor $\mathrm{H}(\mathrm{Y} 402 \mathrm{H})$ and treatment of exudative age-related macular degeneration with ranibizumab. Br J Ophthalmol 2009;93: 610-613.

154 Agosta E, Lazzeri S, Orlandi P, et al: Pharmacogenetics of antiangiogenic and antineovascular therapies of age-related macular degeneration. Pharmacogenomics 2012;13: 1037-1053.

155 Smailhodzic D, Muether PS, Chen J, et al: Cumulative effect of risk alleles in $\mathrm{CFH}$, ARMS2, and VEGFA on the response to ranibizumab treatment in age-related macular degeneration. Ophthalmology 2012;119: 2304-2311.

156 Menghini M, Kloeckener-Gruissem B, Fleischhauer J, et al: Impact of loading phase, initial response and CFH genotype on the long-term outcome of treatment for neovascular age-related macular degeneration. PLoS One 2012;7:e42014.
157 Abedi F, Wickremasinghe S, Richardson AJ, et al: Variants in the VEGFA gene and treatment outcome after anti-VEGF treatment for neovascular age-related macular degeneration. Ophthalmology 2013;120:115-121.

158 Chang W, Noh DH, Sagong M, Kim IT: Pharmacogenetic association with early response to intravitreal ranibizumab for agerelated macular degeneration in a Korean population. Mol Vis 2013;19:702-709.

159 Abedi F, Wickremasinghe S, Richardson AJ, et al: Variants in the VEGFA gene and treatment outcome after anti-VEGF treatment for neovascular age-related macular degeneration. Ophthalmology 2013;120:115-121.

160 Nakata I, Yamashiro K, Nakanishi H, et al VEGF gene polymorphism and response to intravitreal bevacizumab and triple therapy in age-related macular degeneration. Jpn J Ophthalmol 2011;55:435-443.

161 Kokame GT, Yeung L, Lai JC: Continuous anti-VEGF treatment with ranibizumab for polypoidal choroidal vasculopathy: 6-month results. Br J Ophthalmol 2010;94:297-301. 